\title{
Thermal properties of phthalic anhydride- and phenolic resin-cured rigid rod epoxy resins
}

\author{
Wei-Fang Su ${ }^{\mathrm{a}, *}$, Yin-Chung Lee ${ }^{\mathrm{a}}$, Wei-Ping Pan $^{\mathrm{b}}$ \\ ${ }^{\mathrm{a}}$ Department of Materials Science and Engineering, National Taiwan University, Taipei 10627, Taiwan \\ ${ }^{\mathrm{b}}$ Materials Characterization Center, Western Kentucky University, Bowing Green, KY 42101, USA
}

\begin{abstract}
Thermal properties differences between rigid rod tetramethyl biphenyl (TMBP) and flexible diglycidyl ethers of bisphenol A (DGEBA) epoxies were studied using modified differential scanning calorimeter (MDSC), thermogravimetric analyzer (TGA) and dynamic mechanical analyzer (DMA) techniques. These epoxies were cured with phthalic anhydride (PA) and phenolic resin (PF5110), respectively. The PF5110-cured epoxy has better thermal properties than the PA-cured epoxy with a higher glass transition temperature $\left(T_{\mathrm{g}}\right)$ and a higher decomposition temperature. The good thermal properties of the PF5110-cured epoxy are due to the rigid PF5110 structure on the cured epoxy. DGEBA epoxy has a higher decomposition temperature than the rigid rod epoxy when they are cured with PF5110. But, in the PA curing system, rigid rod epoxy has a better thermal stability. These two different results are due to the different structures of curing agents.
\end{abstract}

(C) 2002 Elsevier Science B.V. All rights reserved.

Keywords: Thermal properties; Rigid rod epoxy; Phthalic anhydride; Phenolic resin

\section{Introduction}

Epoxy resins have been commercialized for 50 years. There are thousands of epoxies available in the markets. The basic properties of epoxy resins can be modified in many ways: by blending of different resins, by selection of curing agents and by the use of modifiers and fillers. The epoxy resins have exhibited good thermal properties, chemical resistance and electric insulation through a cross-linking reaction with a curing agent that makes the two-dimensional epoxy structure change to the three-dimensional network structure. These properties of cured epoxies all depend on the structures of curing agents and epoxy resin [1].

\footnotetext{
* Corresponding author.

E-mail address: suwf@ccms.ntu.edu.tw (W.-F. Su).
}

Recently, rigid rod epoxy resins have been developed as a high performance polymer for electronic and aerospace applications because of their good thermal properties. Good mechanical and electrical properties are also obtained. For instance, Mija et al. [2] showed epoxy bearing azomethine groups has a higher thermal stability than flexible diglycidyl ethers of bisphenol A (DGEBA) epoxy. Su et al. [3] demonstrated improved thermal properties for sulfanilamide- or methyl cyclohexane-cured epoxies bearing azomethine or biphenol rigid rod group. Su [4] also cured the biphenol epoxy with trimellitic anhydride and diaminodiphenylsulfone, respectively, and the cured epoxies have exhibited good thermal and electrical properties. Lu et al. [5] have observed good high temperature resistance of methylenedianiline or 4,4'-amino-phenoxy hexanecured biphenol epoxy.

In this study, the DGEBA and tetramethyl biphenyl (TMBP) were cured with phthalic anhydride (PA) and 
phenolic resin (PF5110), respectively. The selection of PA was based on its good electrical insulation and low cost. The choice of PF5110 was for its good thermal stability [6]. The DGEBA has more flexible structure than TMBP. Therefore, the effect of structure of cured epoxy resin with the same curing agent on the thermal properties can be investigated.

\section{Experimental}

\subsection{Materials}

The DGEBA (trade name DER 331) was obtained from Dow Chemical Company with an epoxy equivalent weight of 185.8. The TMBP (trade name RSS1407) was supplied from Shell Chemical Company with an epoxy equivalent weight of 185 . PA was purchased from Aldrich and PF5110 was obtained from Chang Chun Plastics Company with an $\mathrm{OH}$ equivalent weight of 104-105. The structures of two epoxies and two curing agents are shown in Fig. 1.

\subsection{Preparation of cured epoxies}

A DuPont DSC 9900-910 was employed for the determinations of the curing conditions. All samples were prepared from equivalent amount of epoxy resin and curing agent. Fully cured samples show no heat of reaction peaks and no increasing in glass transition temperature $\left(T_{\mathrm{g}}\right)$.

\subsection{Thermal characterization of cured epoxies}

A TA 2920 modulated differential scanning calorimeter (MDSC) $\left(5^{\circ} \mathrm{C} / \mathrm{min}\right.$ in $\left.50 \mathrm{ml} / \mathrm{min}_{2}\right)$ was used to determine the $T_{\mathrm{g}}$ of cured samples. A TA 2980 dynamic mechanical analyzer (DMA) $\left(3{ }^{\circ} \mathrm{C} / \mathrm{min}\right.$ in air, at $1 \mathrm{~Hz}, 20 \mu \mathrm{m}$ amplitude) was used to study $T_{\mathrm{g}}$ of cured samples by measuring the change in modulus and damping properties. The DMA also was used to study the mechanical properties of cured samples. A TA 2950 thermogravimetric analyzer (TGA) $\left(10{ }^{\circ} \mathrm{C} /\right.$ $\min$ in $50 \mathrm{ml} / \mathrm{min}_{2}$ ) was used to study the thermal stability.

Diglycidyl ether of Bisphenol A epoxy (DGEBA)

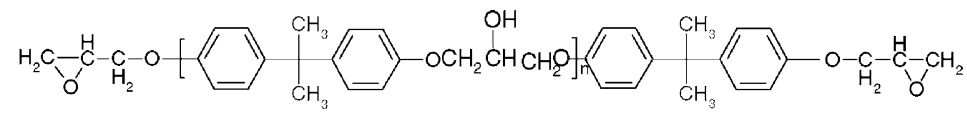

Tetramethyl biphenyl epoxy (TMBP)

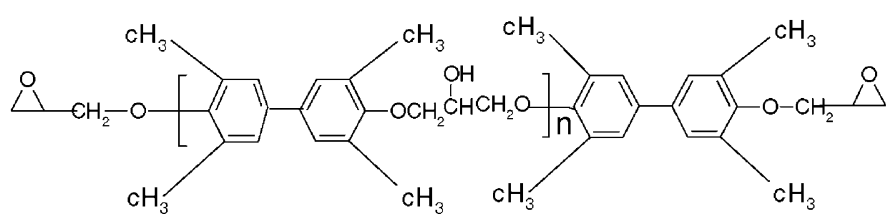

Phthalic anhydride (PA)<smiles>O=C1OC(=O)c2ccccc21</smiles>

Phenolic resin (PF5110)<smiles>CCc1cccc(CC(C)(C)C)c1O</smiles>

Fig. 1. Chemical structures of epoxy resins and curing agent. 


\section{Results and discussion}

Table 1 shows PA-cured epoxy system needs lower temperature and less time than the PF5110-cured epoxy system to be fully cured. The results may be due to the resonance structure of phenyl ring, the PF5110 structure is a weaker nucleophile to open epoxy ring than the anhydride. The data also show that the rigid rod epoxy takes more time or higher temperature to be fully cured which may be due to the bulky structure of tetramethyl groups on biphenyl main chain.

Table 2 summarizes the results of MDSC and DMA results. The MDSC is a general method to obtain the $T_{\mathrm{g}}$ of the samples, but it is less sensitive than DMA. The DMA $T_{\mathrm{g}}$ was obtained by the maximum peak value of $\tan \delta$. From the $T_{\mathrm{g}}$ results, it is very obviously that the rigid rod epoxy has a higher $T_{\mathrm{g}}$ than the flexible epoxy. The bulky group of the TMBP is contributed to high $T_{\mathrm{g}}$. The PF5110-cured system also has a higher $T_{\mathrm{g}}$ than PA-cured system. The aromatic rigid ring on the PF5110 gives high $T_{\mathrm{g}}$.

Table 3 shows the TGA results of different epoxy system. In PA epoxy-cured system, data show TMBP epoxy has better thermal properties than DGEBA epoxy because of the rigid rod main chain and bulky methyl substitutions of TMBP epoxy. However, in the PF5110-cured system, the DGEBA epoxy has a higher

Table 1

Curing conditions of epoxy resin system

\begin{tabular}{lll}
\hline Epoxy/curing agent & \multicolumn{2}{l}{ Curing condition } \\
\cline { 2 - 3 } & Pre-cure $\left({ }^{\circ} \mathrm{C} / \mathrm{h}\right)$ & Post-cure $\left({ }^{\circ} \mathrm{C} / \mathrm{h}\right)$ \\
\hline DGEBA/PA & $125 / 6$ & - \\
DGEBA/PF5110 & $140 / 8$ & $175 / 4,220 / 6,250 / 2$ \\
TMBP/PA & $125 / 8$ & $135 / 2$ \\
TMBP/PF5110 & $140 / 6$ & $175 / 6,220 / 6,250 / 2$ \\
\hline
\end{tabular}

Table 2

$T_{\mathrm{g}}$ of epoxy resin system

\begin{tabular}{lll}
\hline Epoxy/curing agent & \multicolumn{2}{c}{$T_{\mathrm{g}}\left({ }^{\circ} \mathrm{C}\right)$} \\
\cline { 2 - 3 } & MDSC & DMA $(\tan \delta)$ \\
\hline DGEBA/PA & 103 & 122 \\
DGEBA/PF5110 & 149 & 162 \\
TMBP/PA & 126 & 144 \\
TMBP/PF5110 & 182 & 199 \\
\hline
\end{tabular}

Table 3

TGA results of epoxy resin system

\begin{tabular}{llc}
\hline Epoxy/curing agent & $\begin{array}{l}\text { Temperature at } \\
5 \text { wt. } \% \text { loss }\left({ }^{\circ} \mathrm{C}\right)\end{array}$ & $\begin{array}{l}\text { Residue weight } \\
\text { at } 450{ }^{\circ} \mathrm{C}(\%)\end{array}$ \\
\hline DGEBA/PA & 239 & 8.25 \\
DGEBA/PF5110 & 384 & 37.57 \\
TMBP/PA & 248 & 9.64 \\
TMBP/PF5110 & 363 & 37.84 \\
\hline
\end{tabular}

temperature at $5 \%$ weight loss than TMBP epoxy. The bulky methyl group of TMBP epoxy hindered the reactions between PF5110 and epoxy that results in a decreased cross-linking density. Therefore, the PF5110-cured flexible DGEBA epoxy has better thermal properties than the rigid rod TMBP epoxy.

\section{Conclusions}

The curing rate of rigid rod tetramethyl biphenol epoxy is slower than that of the flexible DGEBA epoxy due to the bulky methyl substitution. The rigid rod epoxy has a higher $T_{\mathrm{g}}$ than flexible epoxy cured with the same curing agent because of rigid rod main chain and bulky methyl substitutions on its main chain of TMBP epoxy. In PA-cured system, the thermal stability of rigid rod epoxy is better than that of the flexible epoxy but an opposite result exhibits in the PF5110-cured system. The results indicate the bulky methyl substitution on the biphenyl epoxy main chain has a large steric hindrance effects to reduce the crosslinking density. Thus, a lower thermal stability was obtained for PF5110-cured system.

\section{Acknowledgements}

Financial supports from National Science Council under grant number NSC89-2218-E-002-072 and Western Kentucky University Visiting Scholarship Funds are highly appreciated.

\section{References}

[1] H. Lee, K. Neville, Handbook of Epoxy Resin, California, 1972. McGraw Hill, New York. 
[2] A. Mija, C.N. Cascaval, Gh. Stoica, D. Rosu, B.C. Simionescu, Eur. Polym. J. 32 (6) (1996) 779.

[3] W.F.A. Su, K.C. Chen, S.Y. Tseng, J. Appl. Polym. Sci. 78 (2000) 446.

[4] W.F.A. Su, J. Polym. Sci. A Polym. Chem. 31 (1993) 3251.
[5] M.G. Lu, M.J. Shim, S.W. Kim, J. Appl. Polym. Sci. 75 (2000) 1514.

[6] K.J. Saunders, Organic Polymer Chemistry, Chapman and Hall, London, 1988. 